\title{
Densitometric comparison of 3 occipital regions for suitability of fixation
}

\author{
Chandan Das, MD, ${ }^{1,2}$ Anna G. U. S. Newcomb, MS, ${ }^{2}$ Daniel P. Gaudin, MD, PhD, ${ }^{1}$ and \\ Neil R. Crawford, $\mathrm{PhD}^{2}$ \\ 'Division of Neurological Surgery, University of Toledo Medical Center, Toledo, Ohio; and 2Division of Neurological Surgery, \\ Barrow Neurological Institute, St. Joseph's Hospital and Medical Center, Phoenix, Arizona
}

\begin{abstract}
OBJECTIVE Atlantooccipital fixation is an important technique in the treatment of upper cervical spine instability. Important considerations for implant devices are obtrusiveness and propagation of torque through the device caused by cervical rotation. The authors evaluated the feasibility of 3 regions of the occiput as sites for occipitocervical fixation by examining bone mineral density at these locations.

METHODS Unembalmed occiputs of 9 male and 4 female cadavers were used (mean age at time of death was 61.6 years, range 36-68 years). Studies were undertaken using caliper measurements and dual-energy x-ray absorptiometry of the superior nuchal line (SNL), the external occipital protuberance (EOP), and the inferior nuchal line (INL).

RESULTS Data indicate that the bone at the INL has a similar volumetric bone density as the bone at the SNL, despite having half the thickness. Also, the volumetric bone density increases laterally along the nuchal lines.

CONCLUSIONS Most hardware fixation is centered on stabilization at the EOP and the SNL. On the basis of these radiological results, the INL shows promise as a potential alternative site for screw placement in occipitocervical fixation. http://thejns.org/doi/abs/10.3171/2015.7.SPINE141142
\end{abstract}

KEY WORDS atlantooccipital fixation; bone density; superior nuchal line; cervical

A $\mathrm{N}$ important technique for stabilizing the upper cervical spine is atlantooccipital fixation. Trauma at the craniocervical junction, ${ }^{4}$ damaged ligaments (e.g., the alar and cruciate ligaments), and rheumatoid arthritis ${ }^{3,7}$ with concomitant migration of the odontoid, as well as Down syndrome, ${ }^{27}$ are the most common causes of instability for which patients require fixation procedures. Rarer, but still important, causative factors are congenital conditions, tumors, and infections, which can potentially destroy stabilizing elements. Although numerous patients undergo fixation procedures yearly, there is a lack of agreement among surgeons on the best method for atlantooccipital fixation. Various implants have been used for atlantooccipital fixation, and most of these methods require the use of implants with fixed occipitocervical angles, the use of sublaminar wires, or polymethylmethacrylate , $^{5,8,9}$

Fixation techniques include arthrodesis with HartshillRansford stainless-steel loop and wires ${ }^{21}{ }^{21}$-shaped Luque rod and wires, ${ }^{10,15}$ contoured threaded Steinmann pin and wires ${ }_{19}^{19}$ and rectangular Kirschner rod and wiring. ${ }^{23}$ Rigid fixation techniques of the occipitocervical region with plates or rods fixed on the occiput by screws have also been described.12,24 All of these methods are effective in providing stability; however, it has been shown that the rigid fixation techniques offer improved maintenance of stability with repeated loading. ${ }^{14}$ Within the subset of rigid fixation techniques, Oda et al. conducted a biomechanical analysis of 5 different atlantooccipital fixation techniques, reporting that the pairing of occipital screws and C-2 pedicle screws offers the greatest stiffness of fixation. ${ }^{18}$ Since Oda et al.'s report, fixation systems with occipital plates that are not rigidly fixed to the cervical component, but can be attached with a locking screw mechanism, have been introduced. ${ }^{25}$ Without the constraints of a plate to determine and align screw placement, the location of implant fixation is left to the discretion of the surgeon.

ABBREVIATIONS EOP = external occipital protuberance; INL = inferior nuchal line; $\mathrm{SNL}=$ superior nuchal line; $\mathrm{vBMD}=$ volumetric bone mineral density.

SUBMITTED November 4, 2014. ACCEPTED July 13, 2015.

INCLUDE WHEN CITING Published online January 1, 2016; DOI: 10.3171/2015.7.SPINE141142. 
Roberts et al. ${ }^{22}$ reported that the strength of screw fixation is proportional to the thickness of the bone and that the occipital bone is extremely thin laterally, which is the region where plates are usually applied. Papagelopoulos et al. ${ }^{20}$ showed that a significant correlation exists between pullout strength and both areal and volumetric bone mineral density. A similar correlation has been shown in the spine. ${ }^{26}$ With the flexibility in fixation location provided by newer fixation systems, greater knowledge of occipital morphology as it might relate to biomechanics is needed to ensure the best possible fixation. The purpose of our investigation was to radiographically study the regional bone mineral density of 3 sections of the occiput: the superior nuchal line (SNL), the external occipital protuberance (EOP), and the inferior nuchal line (INL), and to compare their potential as sites for occipitocervical screw fixation.

\section{Methods \\ Specimen Data}

Thirteen unembalmed human adult cadaveric occipital specimens were obtained from local tissue banks and all soft tissue was removed with sharp dissection. The ages at time of death of the cadaveric specimens ranged from 36 to 68 years with an average age of 61.6 years. There were 9 males and 4 females.

\section{Occipital Measurements and Bone Quality Analysis}

The anatomy of each occiput was characterized by measuring the lengths of the right and left SNL and INL (Fig. 1). These length measurements were determined by tracing the path of each line with wire and then measuring the length of the wire with a ruler. The angle measurements were determined by drawing an imaginary line perpendicular to the midline and measuring the deviance of the SNL and INL on the left and right sides, respectively (Fig. 2). Deviance was determined by visually estimating a line that bisects the angle formed by the horizontal and a line drawn between the origin and the distal endpoints of occipital landmarks. This technique has been used in other studies ${ }^{23-25}$ All observations were made in duplicate and by the same individual.

Linear dimensions were determined using electronic calipers modified with custom-machined aluminum Fshaped extensions to enable accurate measurements of curved regions without extensive cutting of bone, as guided by previous studies. ${ }^{26,27}$ Measurements were made at 3 points along each major occipital landmark: the SNL, INL, and EOP. One thickness measurement was taken at the midline, a second measurement at the visible lateral endpoint of both the SNL and INL, a third measurement at the midpoint along the EOP, and a fourth at the periphery of the foramen magnum (Fig. 1). All measurements were taken by 1 individual.

The bone quality of each specimen was analyzed by dual-energy x-ray absorptiometry (DEXA) using a Hologic Discovery W instrument. All samples were thawed before assessment with DEXA to minimize adverse effects of frozen tissue..$^{28}$ Areal bone mineral densities (measured in $\mathrm{g} / \mathrm{cm}^{2}$ ) were obtained along the occipital landmarks of interest (i.e., EOP, SNL, and INL) with a software scan setting for the forearm and subregional analyses of square

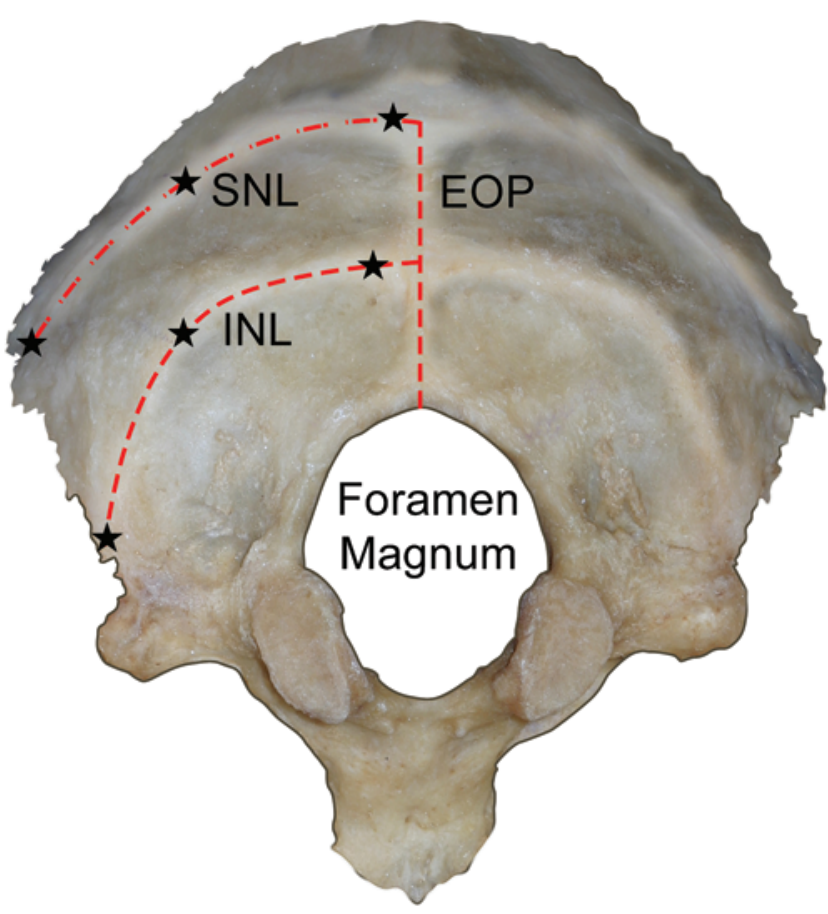

FIG. 1. External occipital landmarks are shown. Stars indicate the medial, central, and lateral regions where measurements were taken. Figure is available in color online only.

regions of interest corresponding to $0.81 \mathrm{~cm}^{2}$. Values for regional volumetric bone mineral density (vBMD; measured in $\mathrm{g} / \mathrm{cm}^{3}$ ) were calculated by dividing the areal BMD of each region by the thickness of bone in that region as measured by calipers.

\section{DEXA Normalization}

To address poor accuracy related to DEXA scanning of thin sections of bone, which has been previously described in the literature, ${ }^{6}$ we constructed a phantom using a 3D printer (Z-Corp.). The phantom contained a 3-mm-thick base and 5 steps of different thicknesses. After our DEXA analysis, the steps were cut out and ash analysis was performed to determine the actual mineral density of each step (Fig. 3). The results were fit to a curve and measured density data were standardized to the actual data.

\section{Statistical Analysis}

Paired Student t-tests were used to compare data from lateral versus medial regions, as well as right versus left sides of each specimen. Repeated-measures ANOVA was used to test for differences in mean bone density and thicknesses among regions. Regions were demarcated by each landmark's geometrical midpoint and 2 endpoints. When a significant difference was found, the Tukey multiple comparison procedure was used to determine which means were statistically different. The level of statistical significance was set at $\mathrm{p}=0.05$.

\section{Results}

\section{Angle and Length}

The INLs exhibit a negative angle of deviance from 


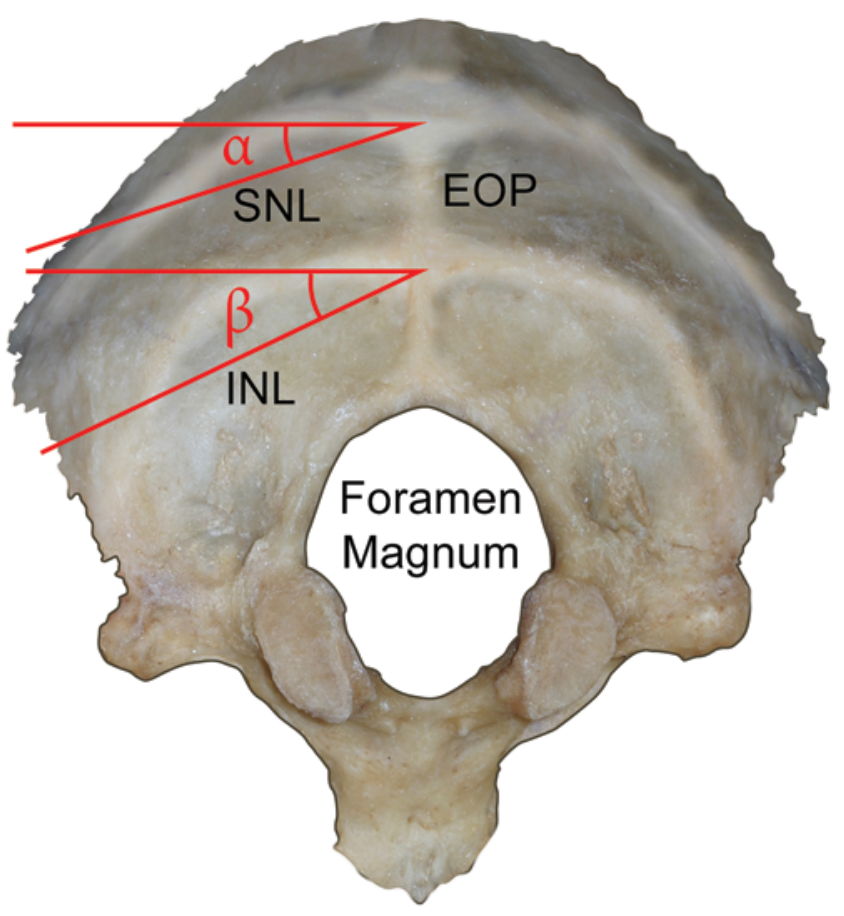

FIG. 2. Angle measurements along the occipital anatomy are shown. Figure is available in color online only.

the midline, whereas SNLs deviate positively (Table 1). However, it should be noted that the data reflected a high amount of variability in the distribution of the deviance angle of the INL. The right and left INLs were similar in length. The right and left SNLs were also similar in length. The INLs were shorter than the SNLs by a mean of $18.0 \mathrm{~mm}$ on the right and a mean of $20.9 \mathrm{~mm}$ on the left.

\section{Thickness Along Occipital Landmarks}

The thickness along the SNL was significantly greater than along the INL at all points away from the EOP (medial, central, and lateral; $\mathrm{p}<0.001)$, and the thickness of the EOP was significantly greater toward the SNL (16.2 \pm $3.9 \mathrm{~mm})$ than toward the INL $(7.2 \pm 2.2 \mathrm{~mm})(\mathrm{p}<0.0001)$. As we proceeded laterally along the major occipital landmarks, the thickness decreased (Table 2), and as we proceeded superiorly along the midline, the thickness increased (Fig. 4). On the basis of paired Student t-tests, the lateral regions were significantly thicker than the medial regions along both nuchal lines $(\mathrm{p}<0.001)$. There were no significant differences between the right and left landmarks at the same linear position ( $p>0.07)$.

\section{Volumetric Density}

The vBMD along the EOP was significantly greater toward the SNL than toward the INL $(\mathrm{p}=0.036)$. There was an increasing trend for vBMD as we proceeded laterally along measured occipital landmarks along both nuchal lines (Fig. 5). However, this increase was only statistically significant along the SNL (lateral vs medial, $\mathrm{p}<0.01$ ), and not along the INL (lateral vs medial, $p>0.06$ ). The differences in vBMD between the SNL and INL were not

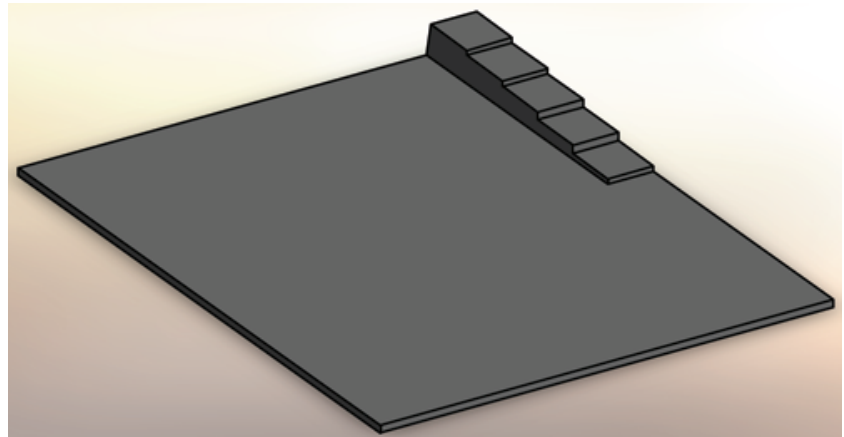

FIG. 3. A SOLIDWORKS (Dassault Systèmes SOLIDWORKS Corp.) model of the phantom is shown. Figure is available in color online only.

statistically significant at any given region away from the EOP (medial, central, or lateral; $\mathrm{p}>0.10$ ).

\section{Discussion}

A major challenge with occipitocervical fixation lies in the inconsistency in morphology of the skull. Developmental processes cause areas of variable density throughout the skull. In the occiput, there are several major landmarks that are commonly used for occipitocervical fusions. Most fusions are fixed at the periphery of the foramen magnum or along the medial SNL. ${ }^{12,15,18,25}$ With the advent of new systems for rod fixation that do not rely on plates, ${ }^{25}$ there are increased options for choosing sites for occipital screw implantation. The surgeon's knowledge of occipital morphology becomes especially important in these cases.

There are many factors to consider in the evaluation of an occipital site for screw implantation, including unicortical versus bicortical screw purchase, bone thickness, and bone density. Neither skull thickness nor density can be easily measured before implantation, but it is well known that the thickness of the occipital bone is pronounced at the midline and along the SNL and INL. ${ }^{16}$ The INL is only marginally thicker than the occipital bone. The mean thickness along the occiput in published studies is only $6.91 \pm 1.40 \mathrm{~mm}$ in adult men and $6.19 \pm 1.69 \mathrm{~mm}$ in adult women as measured by digital calipers on profile radiographs, ${ }^{2}$ whereas our measured thickness of the INL was $7.2 \pm 2.2 \mathrm{~mm}$.

Although there is increased thickness at the midline, the locations of venous sinuses make bicortical purchase along the $\mathrm{EOP}^{17}$ a high risk. Haher et al. ${ }^{13}$ found that the strength of unicortical screws at the EOP was comparable

TABLE 1. Occipital landmark measurements*

\begin{tabular}{clc}
\hline Occipital Landmark & Length $(\mathrm{mm})$ & Angle of Incidence $\left(^{\circ}\right)$ \\
\hline EOP & $48.4 \pm 5.3$ & NA \\
\hline Right SNL & $67.8 \pm 12.4$ & (a) $12.8 \pm 4.6$ \\
\hline Left SNL & $68.0 \pm 8.1$ & (a) $14.3 \pm 7.0$ \\
\hline Right INL & $49.8 \pm 9.9$ & (ß) $-14.9 \pm 15.0$ \\
\hline Left INL & $47.2 \pm 6.0$ & $(\beta)-15.4 \pm 11.9$
\end{tabular}

$\mathrm{NA}=$ not applicable; $\alpha$ and $\beta=$ angles as shown in Fig. 2 .

* Values are presented as the mean \pm SD. 
TABLE 2. Rates of change in thickness and density along major occipital landmarks*

\begin{tabular}{ccc}
\hline Occipital Landmark & Thickness $†$ & Density \\
\hline Right SNL & -0.780 & 0.014 \\
\hline Left SNL & -0.483 & 0.007 \\
\hline Right INL & -0.664 & 0.017 \\
\hline Left INL & -0.747 & 0.015 \\
\hline
\end{tabular}

* Data obtained by linear regression to raw data.

$\dagger$ Millimeter per $\mathrm{cm}$ away from midline.

$\ddagger \mathrm{Gram} / \mathrm{cm}^{3}$ per $\mathrm{cm}$ away from midline.

with that of bicortical screws at other locations. Another important consideration is placement. Biomechanical studies have shown that, compared with laterally placed screws, midline screw fixation allows a longer screw purchase but decreases torsional resistance. Lateral screw placement provides better resistance to rotational stresses than midline placement. ${ }^{1}$ These conclusions are suggestive of nuchal line implant fixation, perhaps in combination with midline fixation, to achieve maximal rotational stiffness and strength.

Papagelopoulos et al. ${ }^{20}$ reported an increase in vBMD with a corresponding decrease in thickness with lateral procession along occipital landmarks, whereas Haher et al. ${ }^{13}$ reported that the pullout strength diminishes with lateral progression away from the external occipital protuberance, similar to the thickness profile presented in Fig. 4. Although both of these groups documented decreased thickness and pullout strength away from the midline, neither study considered the INL specifically. Knowledge of occipital anatomy can help explain these findings by considering that the ratio of cortical (more dense) bone to cancellous bone increases as occipital bone progressively thins.

We believe this notion to be clinically relevant for occipitocervical fixation. Due to the lack of venous sinuses, the denser but thinner lateral bone may be able to accommodate screws with larger diameters, and thereby maximize pullout strength. ${ }^{11}$ Further exploration of the relation-

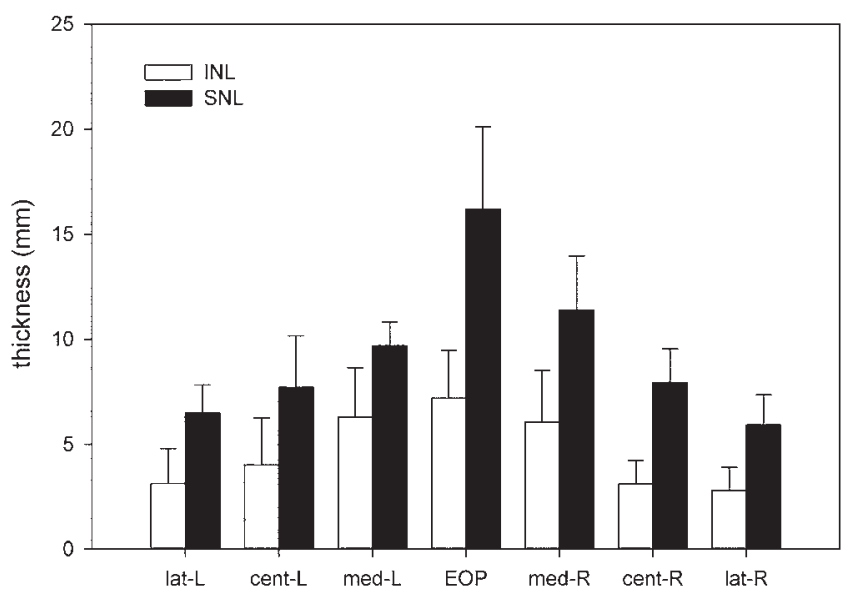

FIG. 4. The mean thicknesses at various occipital bone locations along the INL and SNL are shown (error bars show $1 \mathrm{SD}$ ). cent = central; $\mathrm{L}=$ left; med = medial; $\mathrm{R}=$ right.

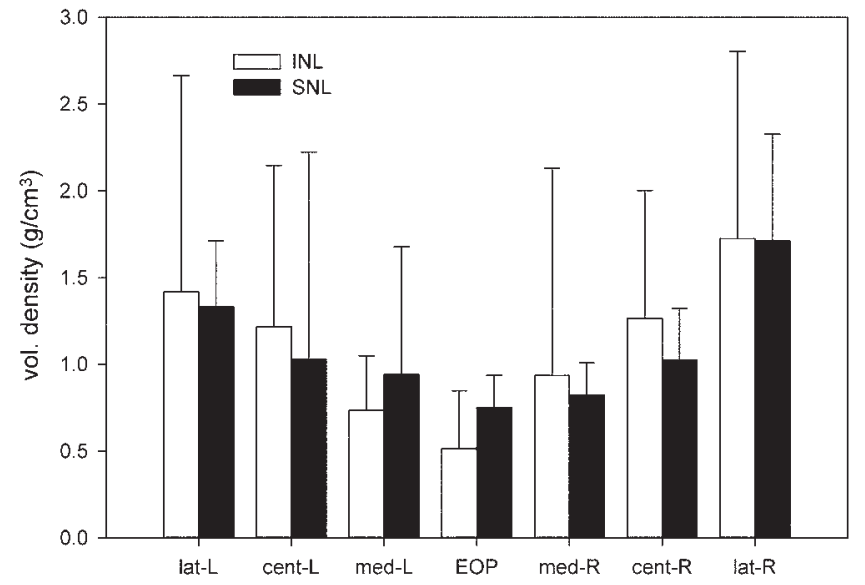

FIG. 5. The mean VBMD at various occipital bone locations along the INL and SNL are shown (error bars show $1 \mathrm{SD}$ ).

ship between occipital bone density and other regions of the body could be the subject of future research. However, in this study, specimens were procured only in the region studied and comparative information was not available for analysis.

\section{Conclusions}

In this study, we have shown that the bone at the INL has a similar vBMD as the bone at the SNL, despite having half the thickness. We have also shown that the vBMD increases (as the bone thickness decreases) laterally along the SNL and INL. On the basis of these results, the INL shows promise for alternative screw placement in occipitocervical fixation, assuming the screws are short and have a finer pitch. Additional biomechanical tests that include pullout testing with different screw type, size, and purchase are warranted.

\section{References}

1. Anderson PA, Oza AL, Puschak TJ, Sasso R: Biomechanics of occipitocervical fixation. Spine (Phila Pa 1976) 31:755761,2006

2. Arntsen T, Kjaer I, Sonnesen L: Skull thickness in patients with skeletal Class II and Class III malocclusions. Orthod Craniofac Res 11:229-234, 2008

3. Babić-Naglić D, Potocki K, Curković B: Clinical and radiological features of atlantoaxial joints in rheumatoid arthritis. Z Rheumatol 58:196-200, 1999

4. Bailey RW, Badgley CE: Stabilization of the cervical spine by anterior fusion. J Bone Joint Surg Am 42-A:565-594, 1960

5. Bryan WJ, Inglis AE, Sculco TP, Ranawat CS: Methylmethacrylate stabilization for enhancement of posterior cervical arthrodesis in rheumatoid arthritis. J Bone Joint Surg Am 64:1045-1050, 1982

6. Carter DR, Bouxsein ML, Marcus R: New approaches for interpreting projected bone densitometry data. J Bone Miner Res 7:137-145, 1992

7. Clark CR, Goetz DD, Menezes AH: Arthrodesis of the cervical spine in rheumatoid arthritis. J Bone Joint Surg Am 71:381-392, 1989

8. Clark CR, Keggi KJ, Panjabi MM: Methylmethacrylate 
stabilization of the cervical spine. J Bone Joint Surg Am 66:40-46, 1984

9. Eismont FJ, Bohlman HH: Posterior methylmethacrylate fixation for cervical trauma. Spine (Phila Pa 1976) 6:347353, 1981

10. Fehlings MG, Errico T, Cooper P, Benjamin V, DiBartolo T: Occipitocervical fusion with a five-millimeter malleable rod and segmental fixation. Neurosurgery 32:198-208, 1993

11. Gausepohl T, Möhring R, Pennig R, Koebke J: Fine thread versus coarse thread: A comparison of the maximum holding power. Injury 32 (Suppl 4):SD1-SD7, 2001

12. Grob D, Dvorak J, Panjabi M, Froehlich, Hayek J: Posterior occipitocervical fusion. A preliminary report of a new technique. Spine (Phila Pa 1976) 16:S17-S24, 1991

13. Haher TR, Yeung AW, Caruso SA, Merola AA, Shin T, Zipnick RI, et al: Occipital screw pullout strength. A biomechanical investigation of occipital morphology. Spine (Phila Pa 1976) 24:5-9, 1999

14. Hurlbert RJ, Crawford NR, Choi WG, Dickman CA: A biomechanical evaluation of occipitocervical instrumentation: screw compared with wire fixation. J Neurosurg 90 (1 Suppl):84-90, 1999

15. Itoh T, Tsuji H, Katoh Y, Yonezawa T, Kitagawa H: Occipitocervical fusion reinforced by Luque's segmental spinal instrumentation for rheumatoid diseases. Spine (Phila Pa 1976) 13:1234-1238, 1988

16. Naderi S, Usal C, Tural AN, Korman E, Mertol T, Arda MN: Morphologic and radiologic anatomy of the occipital bone. J Spinal Disord 14:500-503, 2001

17. Nadim Y, Lu J, Sabry FF, Ebraheim N: Occipital screws in occipitocervical fusion and their relation to the venous sinuses: an anatomic and radiographic study. Orthopedics 23:717-719, 2000

18. Oda I, Abumi K, Sell LC, Haggerty CJ, Cunningham BW, McAfee PC: Biomechanical evaluation of five different occipito-atlanto-axial fixation techniques. Spine (Phila Pa 1976) 24:2377-2382, 1999

19. Papadopoulos SM, Dickman CA, Sonntag VK, Rekate HL, Spetzler RF: Traumatic atlantooccipital dislocation with survival. Neurosurgery 28:574-579, 1991

20. Papagelopoulos PJ, Currier BL, Stone J, Grabowski JJ, Larson DR, Fisher DR, et al: Biomechanical evaluation of occipital fixation. J Spinal Disord 13:336-344, 2000

21. Ransford AO CH, Pozo JL, Thomas NP, Nelson IW: Craniocervical instability treated by contoured loop fixation. $\mathbf{J}$ Bone Joint Surg Br 68:173-177, 1986

22. Roberts DA, Doherty BJ, Heggeness MH: Quantitative anat- omy of the occiput and the biomechanics of occipital screw fixation. Spine (Phila Pa 1976) 23:1100-1108, 1998

23. Sakou T, Kawaida H, Morizono Y, Matsunaga S, Fielding JW: Occipitoatlantoaxial fusion utilizing a rectangular rod. Clin Orthop Relat Res (239):136-144, 1989

24. Smith MD, Anderson P, Grady MS: Occipitocervical arthrodesis using contoured plate fixation. An early report on a versatile fixation technique. Spine (Phila Pa 1976) 18:19841990, 1993

25. Stock GH, Vaccaro AR, Brown AK, Anderson PA: Contemporary posterior occipital fixation. J Bone Joint Surg Am 88:1642-1649, 2006

26. Tabensky AD, Williams J, DeLuca V, Briganti E, Seeman E: Bone mass, areal, and volumetric bone density are equally accurate, sensitive, and specific surrogates of the breaking strength of the vertebral body: an in vitro study. J Bone Miner Res 11:1981-1988, 1996

27. Taggard DAMA, Menezes AH, Ryken TC: Instability of the craniovertebral junction and treatment outcomes in patients with Down's syndrome. Neurosurg Focus 6(6):e3, 1999

28. Wähnert D, Hoffmeier KL, Lehmann G, Fröber R, Hofmann GO, Mückley T: Temperature influences on DEXA measurements: bone mineral density acquisition in frozen and thawed human femora. BMC Musculoskelet Disord 10:25, 2009

\section{Disclosures}

The authors report no conflict of interest concerning the materials or methods used in this study or the findings specified in this paper.

\section{Author Contributions}

Conception and design: Crawford, Das, Newcomb. Acquisition of data: Das, Newcomb. Analysis and interpretation of data: Das, Newcomb. Drafting the article: Das, Newcomb. Critically revising the article: all authors. Reviewed submitted version of manuscript: all authors. Statistical analysis: Das, Newcomb. Administrative/technical/material support: Crawford, Newcomb. Study supervision: Crawford.

\section{Correspondence}

Neil R. Crawford, c/o Neuroscience Publications, Barrow Neurological Institute, St. Joseph's Hospital and Medical Center, 350 W. Thomas Rd., Phoenix, AZ 85013. email: neil.crawford@ dignityhealth.org. 